\title{
SISTEM PERMAINAN LEGO TIGA DIMENSI DENGAN KAMERA LEAP MOTION
}

\author{
Setiawardhana ${ }^{1}$, Sigit Wasista ${ }^{2}$, Dyah Agustinah Wulandari ${ }^{3}$ \\ Program Studi D4 Teknik Komputer \\ Departemen Informatika dan Komputer Politeknik Elektronika Negeri Surabaya \\ Kampus PENS, Jalan Raya ITS Sukolilo, Surabaya 60111 \\ setia@pens.ac.id,wasista@pens.ac.id, dyahagustinahw@ce.student.pens.ac.id
}

\begin{abstract}
Abstrak
Lego merupakan sebuah mainan yang berbentuk kotak, segitiga, persegi panjang, dan lingkaran yang memiliki panjang, lebar, dan tinggi. Lego juga memiliki aneka warna yang dapat disusun sesuai dengan kombinasi yang berbeda dan sangat populer diseluruh dunia terutama bagi anak - anak. Penelitian ini bertujuan untuk mengembangkan aplikasi interaktif kamera Leap Motion untuk penyusunan lego tiga dimensi. Interaktif Lego ini dapat mendeteksi gerakan gerak tangan, jari dan benda sebagai data masukan ke kamera dan dapat menyusun setiap lego sesuai dengan keinginan pengguna. Sistem le g o tiga dimensi dibuat dengan 3DUnity. Metode tracking dibangun dengan memanfaatkan pustaka yang disediakan oleh perusahaan Leap Motion dengan metode skeletal tracking. Pembangunan aplikasi ini menggunakan model skeletal 3D dapat menyusun Lego dengan klasifikasi gesture sehingga permainan tampak lebih interaktif pada komputer dengan gerakan tangan atau jari di udara. Fitur-fitur interaktif pada aplikasi seperti grab, motion, put, gesture dan touch dapat dijalankan sesuai tahap pengujian. Hand Model Visual Graphic pada sistem dapat menjangkau area interaksi bermain antara $15 \mathrm{~cm}$ hingga $35 \mathrm{~cm}$ diatas Leap Motion dan mencapai jangkauan sempurna pada 25 $\mathrm{cm}$ hingga $35 \mathrm{~cm}$, sedangakan didepan dan dibelakang Leap Motion jangkauan terdapat pada $15 \mathrm{~cm}$ hingga 35 $\mathrm{cm}$ dan mencapai jangkauan sempurna pada $20 \mathrm{~cm}$ hingga $35 \mathrm{~cm}$. Sistem memiliki hasil pengujian 'Main CPU' dengan nilai dibawah $20 \mathrm{~ms}$. Peneliti juga menguji sistem aplikasi ini pada beberapa pengguna dengan hasil prosentase dari pengujian grafis $80 \%$ dengan hasil baik, dan pengujian gameplay $70 \%$ dengan hasil baik.
\end{abstract}

Kata kunci: 3D Unity, Leap Motion, Lego 3 Dimensi, Skeletal Tracking

\section{Latar Belakang}

Lego merupakan permainan yang sangat populer di dunia terutama bagi anak-anak. Permainan Lego memiliki berbagai manfaat bagi pertumbuhan anak dengan mengenali berbagai macam warna dan bentuk melalui Lego. Permainan ini memungkinkan anak-anak untuk menyusun kombinasi kotak mulai dari dua kotak yang dapat dibuat 24 kombinasi berbeda sampai 6 kotak dengan 915 juta kemungkinan kombinasi. Semakin pesat perkembangan teknologi di era moderen ini, perkembangan Lego juga semakin bervariatif salah satunya dengan menggunakan 2 Dimensi ataupun 3 Dimensi sebagai bentuk pengembangannya. Banyak sekali teknologi pengembangan permainan Lego seperti menggunakan Android, Unity, dan lain sebagainya.

Penelitian sebelumnya yang telah dilakukan oleh Ayung Candra Padmasari[1], merancang sebuah media berbasis teknologi virtual sebagai inovasi pengembangan ruang kelas dalam bentuk 3D. Pada penelitian ini dibagi menjadi 3 tahap diantaranya proses perancangan desain awal, skenario interaksi dalam ruang virtual berbentuk
Finite State Machine. Skenario interaksi dengan hand gesture menjadi pilihan peneliti untuk mendesain skenario. Hasil penelitian ini nantinya akan dikendalikan oleh rancangan agen berupa manusia lain yang diambil dari assetstore Unity $3 D$ dengan konsep perintah terdiri atas tap gesture, keytap gesture, circle gesture dan swipe gesture.

Penelitian sebelumnya yang telah dilakukan oleh Adam G. Yowanda et al[2], merancang papan tulis virtual dengan kamera leap motion berbasis gerakan yaitu dengan menangkap coretan-coretan di udara yang dilakukan oleh pengguna dan menjadikannya tertulis dilayar komputer. Pembangunan aplikasi ini akan di titik beratkan pada algoritma penghalusan garis RamerDouglas-Peucker, menggambar garis dengan tanpa sentuhan, pembangunan kontrol nirsentuh, dan sebuah metode menulis baru dengan menggunakan Handwriting Board sebagai alat bantu menulis.

Penelitian sebelumnya yang telah dilakukan oleh Michal Nowicki et al [3], mempelajari kemungkinan baru untuk interface gesture yang muncul dengan Leap Motion. Hasil dari penelitian ini adalah Leap Gesture yang 
didedikasikan untuk para pengembang Leap Motion Controller yang berisi algoritma yang memungkinkan dalam pembelajaran mengenali gerakan. Peneliti memeriksa data yang diberikan oleh sensor dalam konteks pengenalan pose tangan (static gesture), pergerakan tangan (dynamic gestures), dan pengenalan jari. penelitian tersebut berisi evaluasi pengaturan fitur berbeda yang signifikan sehingga berdampak pada tingkat pengenalan.

Penelitian sebelumnya yang telah dilakukan oleh Afdhol Dzikri et al[4], tentang pelacakan jari tangan berdasarkan data kedalaman yang dimiliki oleh Leap Motion yaitu tiga komponen vektor sebagai posisi dalam ruang tiga dimensi (sumbu koordinat XYZ) dan jarak maksimum jari yang terdeteksi dengan asumsi lima jari tangan terdeteksi oleh Leap Motion yaitu berkisar antara -0.3 sampai 0.6 meter terhadap sumbu koordinat XYZ.

Berangkat dari beberapa peneliti sebelumnya, peneliti bertujuan membuat aplikasi edukatif interaktif khususnya bagi anak-anak yaitu Interaktif Lego dengan kamera Leap Motion dengan lingkup pengembangan pencocokan pola pada tiap Lego menggunakan Symmetrical Block, pemodelan tangan yang digunakan yaitu $3 D$ Hand Model, Skenario tiap gestures terdiri dari motion, grab, put, dan tap gesture.

\subsection{Metode Perancangan dan Pembuatan Sistem Interaktif Lego Tiga Dimensi}

Pembuatan sistem yaitu meliputi pembuatan sistem deteksi dengan leap motion dengan hand gesture, melakukan kalibrasi terhadap sistem, pembuatan logo, pencocokan pola, kompilasi dan visualisasi grafis secara tiga dimensi.

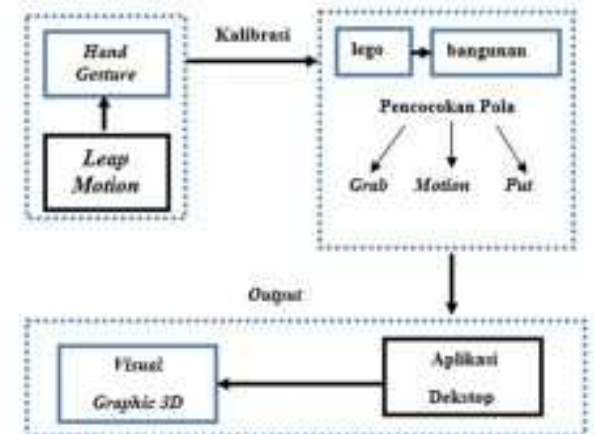

Gambar 2.1. Diagram Perancangan Sistem

Pembuatan antarmuka sistem dibuat dengan menggunakan $\mathrm{k}$ menggunakan Unity3D personal versi 5.3.4f1. Komponen yang disertakan adalah Hand Controller Sand Box sebagai ruang interaksi bermain Lego dengan penambahan directional light sebagai pencahayaan.

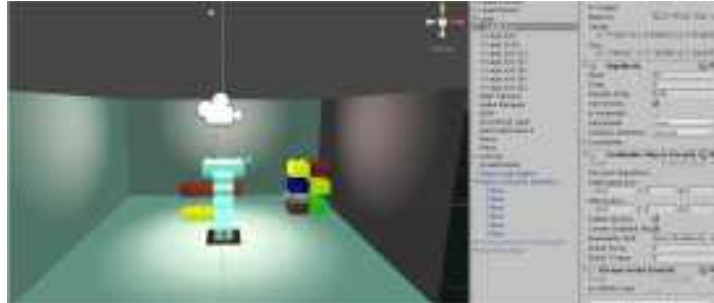

Gambar 2.2. Perancangan Interaksi Ruang Bermain

Pembuatan asset yang diperlukan untuk membangun game Lego yaitu balok-balok berbeda ukuran yang nantinya disusun antara balok satu dengan balok yang lain. Pembuatan balok tersebut tinggal mengambil dari asset yang disediakan Unity dengan menambahkan script agar balok dapat digerakkan dan dapat berpindah kearah mana saja seperti balok pada dunia nyata. Skrip yang ditambahkan yaitu script Grabbable Object dan Grabbing Hand.

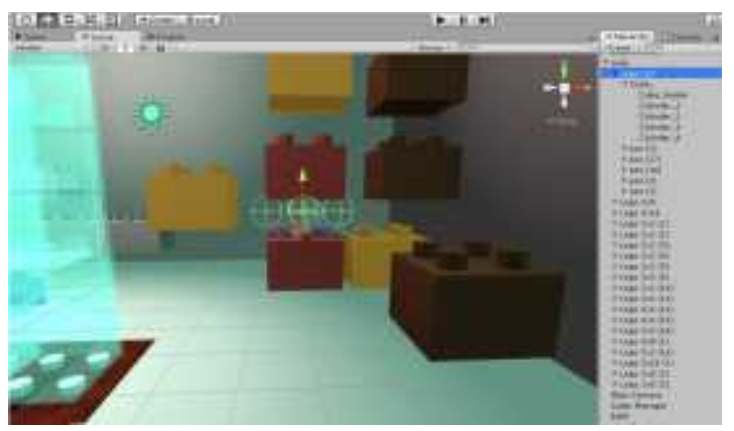

Gambar 2.3. Pembuatan Asset Lego

Asset Lego terdapat 3 macam bentuk yaitu $2 \times 2,2 \times 4,2 \times 8$. Setiap Lego diberi material yang berbeda untuk tekstur warnanya. Lego terdiri dari $3 D$ cube dan $3 D$ cillynder. Setiap Lego memiliki pos-pos yang nantinya menjadi titik penancapan Lego-Lego.

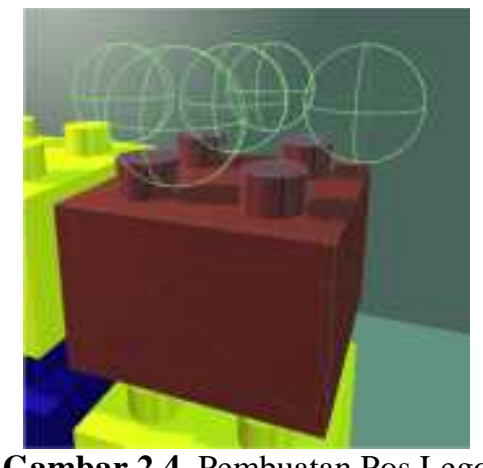

Gambar 2.4. Pembuatan Pos Lego

Pos-pos Lego merupakan bentuk dari posisi Lego tiap balok yang di hide. Setiap pos mewakili setiap macam posisi yang memungkinkan balok Lego terpasang pada tiap titik. Agar balok tidak tembus ketika disusun satu persatu maka diberi Box Collider seperti pada gambar berikut. 


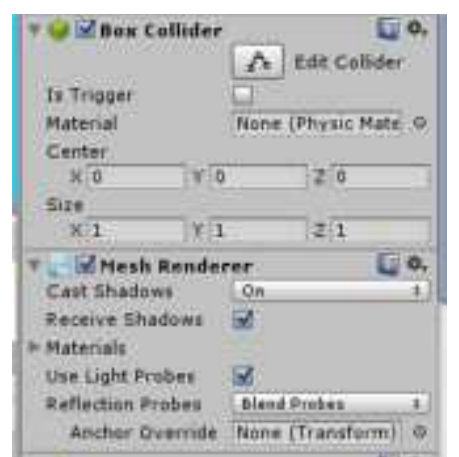

Gambar 2.5. Penambahan collider

Nilai collider yang terlalu besar akan mempengaruhi proses interaksi antara 3D model tangan dan objek. Balok akan mudah terpental setiap kali tangan menyentuh objek balok tersebut jika nilai collider terlalu besar. Leap Motion Asset belum mendukung interaksi antara tangan dengan obyek dengan kondisi 'tanpa menembus' obyek. Penyusunan Lego dapat tersusun rapi bila diberi trigger berupa Lego kinematik, yang merupakan Lego trigger dari semua susunan balok. Agar tidak berubah posisi maka lakukan aktivasi pada bagian Rigid Body yaitu is Kinematik dan Is Starter Lego. Hal ini dilakukan agar Lego kinematik berubah posisi dan arah.

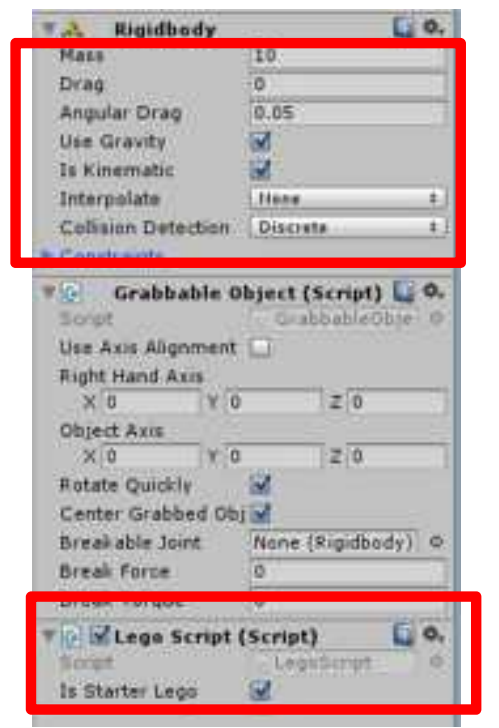

Gambar 2.6. Lego Kinematik

Rencana pengembangan aplikasi ini yaitu membuat dua macam model 3D tangan yang berbeda, yaitu human skin model dan robot model. Pada model tangan yang digunakan dengan memberikan script pada Hand Controller yaitu script Rigid Full Hand pada Hand Phisiscs Mode.

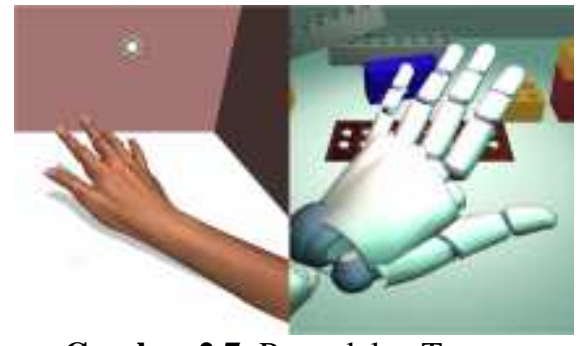

Gambar 2.7. Pemodelan Tangan

Penambahan interaksi menu tombol pada aplikasi menggunakan touch emulation pada Leap Motion sehingga pengguna dapat menekan tombol tanpa harus berentuhan langsung dengan layar.

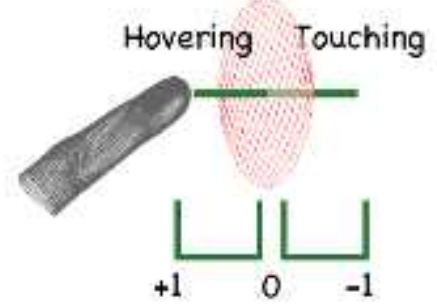

Gambar 2.8. Hovering dan Touching

Touch Zone mengidentifikasi apakah Leap Motion menganggap pointable mendekati permukaan sentuh atau tidak. Jarak sentuh hanya berlaku ketika pointable pada hover zone atau touch zone, dengan jarak nilai normal kisaran [+1..1]. Ketika pointable memasuki hover zone, jarak sentuh yaitu 1.0 dan jarak menurun menuju 0 jika pointable mendekati permukaan sentuh None merupakan pointable yang terlalu jauh dari area Leap Motion, Hover Zone merupakan area membidik atau melayang, dan Touch Zone merupakan area sentuh virtual.

\subsection{Hasil Pembuatan Sistem Permainan}

Sistem yang telah dibuat terdiri menu utama, sub menu, tanda loading ke ruang bermain, area ruang bermain, tanda pause, dan tanda berhasil. Hasil menu utama terdiri dari tombol play, visualizer, exit dan tombol help. Berikut merupakan user interface dari menu utama.

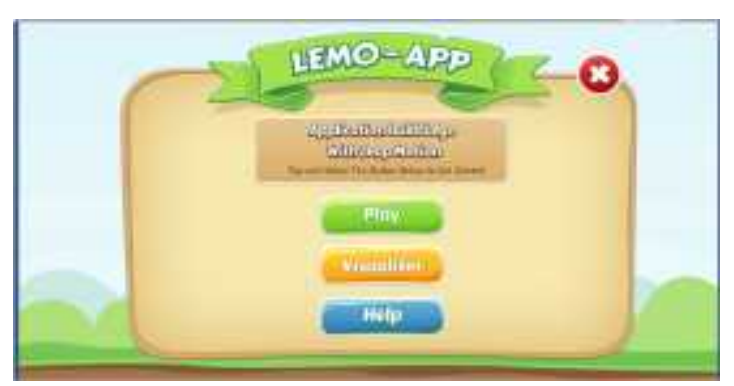

Gambar 2.9. Menu Utama 
Hasil menu sub play terdiri dari 6 tombol level. Berikut merupakan user interface dari sub menu play. Tiap sub menu play memiliki tingkat kesulitan yang berbeda, semakin tinggi level maka semakin rumit. Aplikasi ini dapat dikatakan sebagai game namun dalam hal ini tidak ada poin ketika dapat melanjutkan kelevel selanjutnya, aplikasi guna melatih ketangkasan sensor motorik dan daya tahan tangan ketika bermai seolah-olah diudara dengan tangan melayang. Pengguna dapat memilih level mana yang diinginkan untuk bermain.

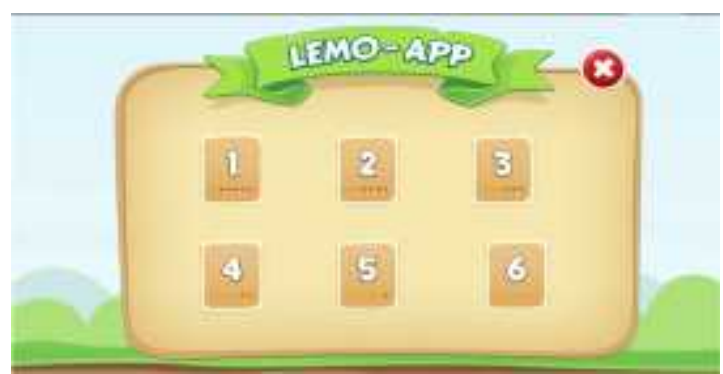

Gambar 2.10. Sub Menu Utama

Hasil menu user interface loading yang akan masuk kedalam ruang bermain sesuai sub menu level yang dipilih seperti pada gambar 11 .

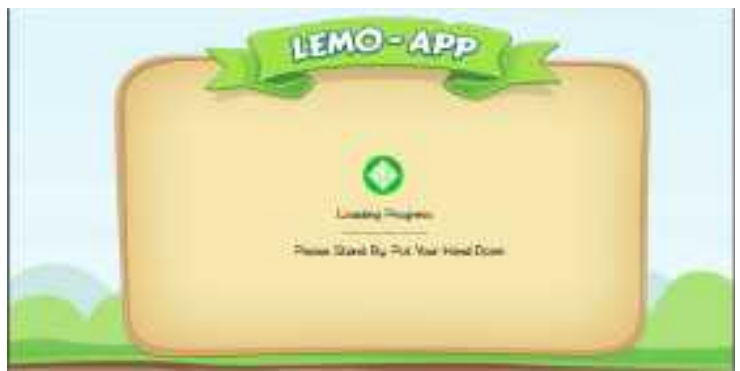

Gambar 2.11. UI Loading

Hasil user interface ruang bermain yang berisi balok-balok Lego, gambar instruksi, dan level permainan yang sedang dilakukan seperti pada gambar 12. Setiap level berbeda macam warna dan jenis balok yang lebih kompleks

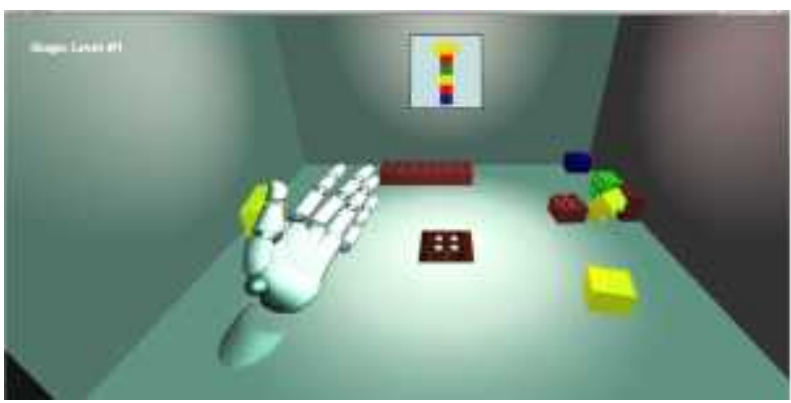

Gambar 2.12. Ruang Bermain

Hasil desain UI Pause digunakan ketika pengguna keluar dari area jangkauan Leap Motion atau tidak sedang berada pada area jangkauan Leap Motion.

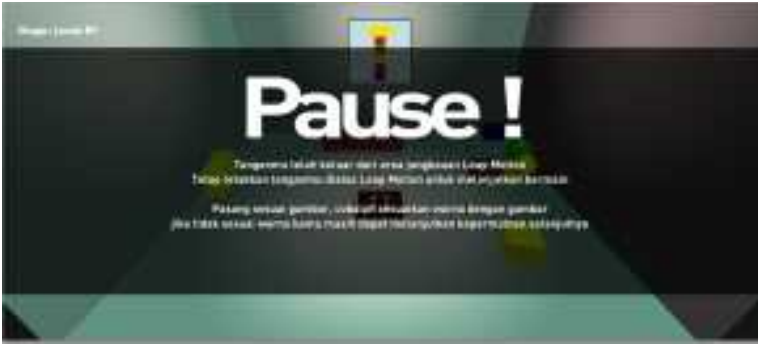

Gambar 2.12. Peringatan Pause

Hasil desain UI Berhasil ketika pengguna sukses menyusun Lego sesuai dengan instruksi.

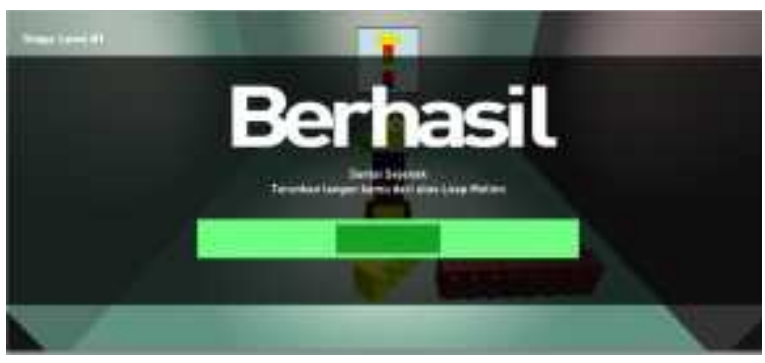

Gambar 2.13. Status Berhasil

Hasil desain UI Help yang merupakan informasi bagaimana cara bermain aplikasi ini, dan berupa saran-saran agar pengguna tidak cepat lelah ketika bermain seperti pada gambar 14

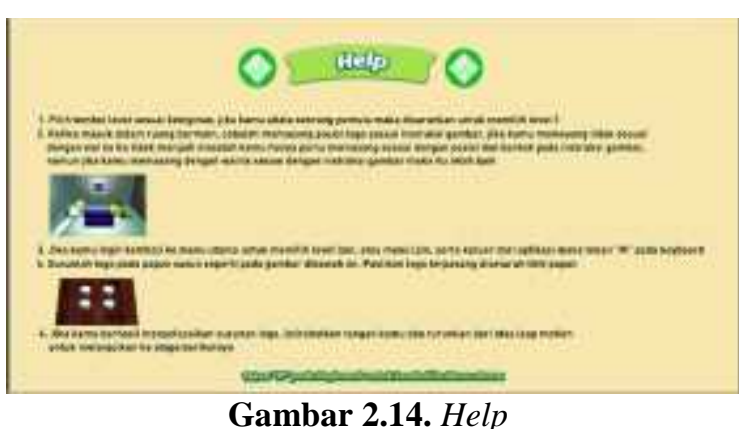

\subsection{Pengujian Posisi Presisi Tangan}

Lingkungan uji coba sistem sebagai berikut :

a. Perangkat Keras (Hardware)
1. Processor
: Intel(R)
Core(TM) i5
2. Harddisk
: Kapasitas 250GB
3. RAM
$: 10 \mathrm{~GB}$
4. Leap Motion

b. Perangkat Lunak (Software)

1. Sistem Operasi : Windows $10-$ 64 bit

2. Software Build : Unity3D 5.3.4f1 - 64bit, Leap Motion Control Panel, Leap Motion Visualizer, Camtasia Recorder.

Pengujian presisi tangan dilakukan dengan tujuan untuk menganalisa apakah performa dari gerak tangan graphic 3D pada sistem sama dengan 
visualizer default Leap Motion. Pengujian ini dilakukan random terhadap beberapa interaksi dan gerak 3D model tangan pada sistem dengan hasil dari visualizer Leap Motion.Berikut merupakan hasil dari percobaan presisi tangan nyata dengan graphic 3D tangan.

\subsection{Pengujian Fungsionalitas}

Tabel 2 dan tabel 3 merupakan hasil dari pengujian fungsionalitas tiap titik Lego sebanyak 16 kali dinyatakan berhasil dan dapat tertancap sesuai posisi titip tiap-tiap Lego dengan baik. Sehingga dapat dikatakan fungsi Lego dapat memenuhi kebutuhan pengguna seperti Lego didunia nyata.

\subsection{Pengujian Filtering}

Tabel 4 merupakan pengujian nilai filtering terhadap graphic, semakin tinggi nilai filtering yang diberikan semakin halus dan mudah melakukan interaksi dengan obyek. Hal ini dilihat dari nilai graphic dengan satuan frame persecond (Fps), namun dalam hal ini jika menambahkan filtering tinggi akan mempengaruhi performa sistem jika spesifikasi PC kurang memadai.

Tabel 3.1. Pengujian nilai filtering terhadap graphic

\begin{tabular}{|c|c|c|}
\hline No & Filtering Value & Graphics $(\mathrm{Fps})$ \\
\hline 1 & 0 & 66.2 \\
\hline 2 & 1 & 68.3 \\
\hline 3 & 5 & 71.4 \\
\hline 4 & 10 & 73.4 \\
\hline 5 & 15 & 83.0 \\
\hline 6 & 20 & 84.2 \\
\hline 7 & 25 & 86.7 \\
\hline
\end{tabular}

\subsection{Pengujian Jarak Penggunaan Sistem}

Tabel 5 merupakan pengujian jarak deteksi tangan terhadap Leap Motion. Hasil dari pengujian tersebut dapat dilihat bahwa jarak $40 \mathrm{~cm}$ tidak mendeteksi adanya tangan pada area Leap Motion, hal ini ditandai dengan tidak adanya blue line pada tangan di viewer Leap Motion. Sedangkan jarak antara $35 \mathrm{~cm}$ hingga $15 \mathrm{~cm}$ dapat terdeteksi penuh oleh Leap Motion, dan jarak $10 \mathrm{~cm}$ kurang terdeteksi karena terlalu dekat dan terpotong bagian jari-jari sekitar telunjut, jari tengah, dan jari manis.

\subsection{Pengujian Performa Aplikasi}

Tabel 6 merupakan tabel pengujian performa aplikasi dilihat dari kerja main CPU dan Render Thread. Pada pengujian tabel 6 dilakukan load level secara berurutan dari level 1 hingga level 6. Setiap level memiliki 3 stage yang setiap stage memiliki kerumitan pemasangan Lego dengan banyak Lego yang akan dipasang, otomatis semakin banyak pula frame yang dirender. Hal ini dilihat dari performa Main CPU (ms) yang dibutuhkan dalam memproses ratusan obyek dalam satuan waktu.

Tabel 4.1. Pengujian Performa Aplikasi

\begin{tabular}{|c|c|c|c|}
\hline No & Load Level & $\begin{array}{c}\text { Main CPU } \\
(\mathrm{ms})\end{array}$ & $\begin{array}{c}\text { Render Thread } \\
(\mathrm{ms})\end{array}$ \\
\hline 1 & Level 1 ( stage 1 $)$ & 12.8 & 4.9 \\
\hline 2 & Level 1 ( stage 2 $)$ & 13.2 & 4.8 \\
\hline 3 & Level 1 ( stage 3) & 13.9 & 5.2 \\
\hline 4 & Level 2 ( stage 1) & 12.9 & 5.1 \\
\hline 5 & Level 2 ( stage 2) & 14.2 & 4.9 \\
\hline 6 & Level 2 ( stage 3) & 12.9 & 5.6 \\
\hline 7 & Level 3 ( stage 1) & 13.6 & 5.8 \\
\hline 8 & Level 3 ( stage 2) & 13.7 & 6.2 \\
\hline 9 & Level 3 ( stage 3) & 13.9 & 5.9 \\
\hline 10 & Level 4 ( stage 1) & 13.8 & 6.4 \\
\hline 11 & Level 4 ( stage 2) & 12.8 & 7.3 \\
\hline 12 & Level 4 ( stage 3) & 13.4 & 7.7 \\
\hline 13 & Level 5 ( stage 1) & 14.7 & 7.8 \\
\hline 14 & Level 5 ( stage 2) & 14.8 & 8.1 \\
\hline 15 & Level 5 ( stage 3) & 15.0 & 8.1 \\
\hline 16 & Level 6 ( stage 1) & 15.3 & 8.3 \\
\hline 17 & Level 6 ( stage 2) & 15.7 & 7.9 \\
\hline 18 & Level 6 ( stage 3) & 16.5 & 7.8 \\
\hline
\end{tabular}

Dapat dilihat pada tabel pengujian bahwa semakin tinggi level atau semakin banyak level yang diproses maka semakin lama pula Main CPU memproses, namun perlu diketahui dalam hal ini paling lama Main CPU memproses adalah $16.5 \mathrm{~ms}$, dan hal tersebut tidak mengganggu proses permainan dikarenakan masih dibawah $20 \mathrm{~ms}$, dan dalam batas normal. Demikian dengan Render Thread yang merupakan waktu yang dibutuhkan untuk proses render tiap framerate masih dalam batas normal yaitu kurang dari $10 \mathrm{~ms}$.

\subsection{Pengujian Grafis}

Hasil pengujian grafis adalah kepuasan pengguna mengenai grafis dan tampilan dari sistem. Pengujian ini akan menitik beratkan pada tanggapan dan reaksi pengguna ketika bermain teknologi baru yang belum mereka gunakan sebelumnya. Berikut adalah hasil dari pengujian grafis.

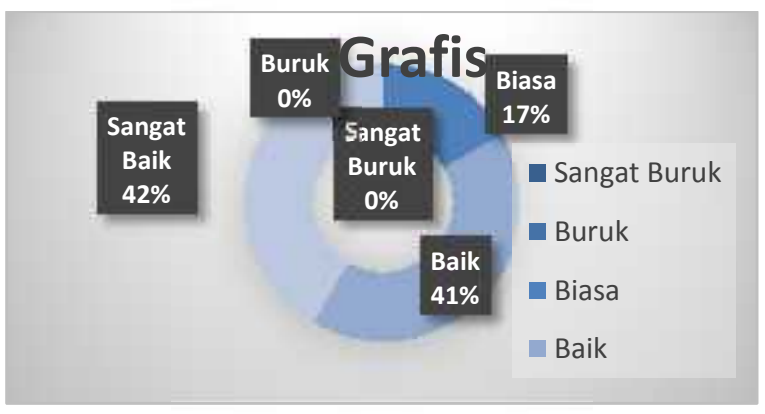

Gambar 4.1. Hasil Pengujian Kualitas Grafis 
Dari Gambar 15 menunjukkan bahwa pengguna menilai kualitas grafis dari sistem ini $41 \%$ baik, $42 \%$ sangat baik, $17 \%$ untuk biasa. Sebagian besar pengguna menilai grafis dari sistem baik. Dari hasil kuisioner maka didapat tanggapan sebagai berikut :

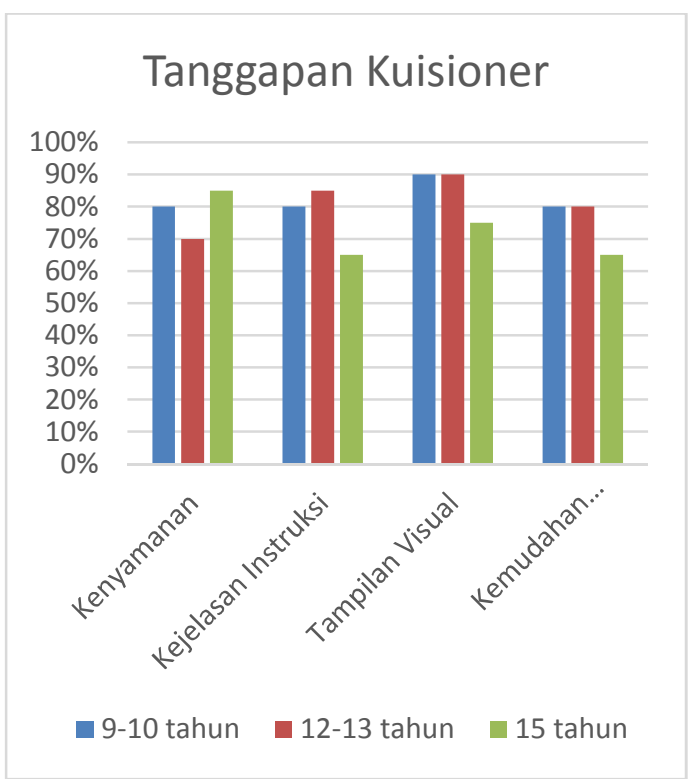

Gambar 4.2. Hasil Kuisioner

Dari hasil tanggapan kuisioner gambar 16 maka didapat kesimpulan bahwa pada pengguna merasa nyaman ketika bermain aplikasi dengan perangkat Leap Motion. Penggunanya juga memberikan tanggapan baik atas kejelasan instruksi aplikasi yang diberikan, serta mengapresiasi tampilan visual aplikasi yang menarik dari segi animasi dan tombol. Faktor kemudahan mengoperasikan aplikasi juga mendapat tanggapan baik oleh para pengguna.

\subsection{Pengujian Gameplay}

Gameplay adalah cara pengguna dalam berinteraksi dengan sebuah permainan. Dalam hal ini, pengguna akan mencoba beberapa fitur, stage, dan level yang ada pada permainan. Informasi yang didapat dari pengujian ini adalah kemampuan pengguna untuk mencoba semua level permainan dan menguji balancing atau keseimbangan dalam permainan. Berikut adalah hasil dari pengujian. Dari Gambar 17 menunjukkan bahwa pengguna menilai gameplay dari sistem ini $10 \%$ sangat baik, $50 \%$ baik, dan $0 \%$ untuk sangat buruk, $10 \%$ buruk, dan $30 \%$ biasa. Sebagian besar pengguna menilai gameplay dari sistem adalah baik. Hal tersebut menunjukkan bahwa desain level yang ditawarkan peneliti mendapatkan tanggapan positif kepada pengguna.

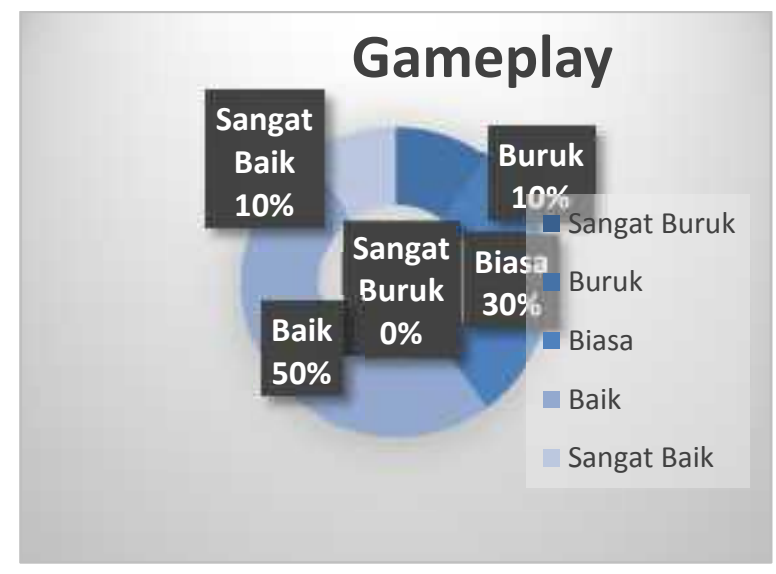

Gambar 17. Hasil Pengujian Gameplay

\subsection{Kesimpulan}

Berdasarkan uji coba yang dilakukan, maka dapat disimpulkan sebagai berikut :

1. Fitur-fitur interaktif pada aplikasi seperti grab, motion, put, gesture dan touch dapat dijalankan sesuai tahap pengujian.

2. Hand Model Visual Graphic pada sistem dapat menjangkau area interaksi bermain antara $15 \mathrm{~cm}$ hingga $35 \mathrm{~cm}$ diatas Leap Motion dan mencapai jangkauan sempurna pada $25 \mathrm{~cm}$ hingga $35 \mathrm{~cm}$, sedangakan didepan dan dibelakang Leap Motion jangkauan terdapat pada $15 \mathrm{~cm}$ hingga $35 \mathrm{~cm}$ dan mencapai jangkauan sempurna pada $20 \mathrm{~cm}$ hingga $35 \mathrm{~cm}$.

3. Hasil analisa yang dilakukan terhadap 3D model tangan ketika melakuakan pengambilan obyek ataupun ketika memegang obyek tidak dapat dibangun dengan tidak tertembus dikarenakan Leap Motion belum mendukung asset yang agar 3D model tangan terlihat lebih natural ketika berinteraksi dengan obyek.

4. Sistem dikatakan normal dengan pembuktian hasil pengujian Main CPU $16.5 \mathrm{~ms}$ pada semua load level, dikatakan normal kurang dari $20 \mathrm{~ms}$, dan render thread $8.3 \mathrm{~ms}$ dikatakan normal yaitu kurang dari $10 \mathrm{~ms}$.

5. Peneliti menguji aplikasi personal pada beberapa pengguna dengan hasil prosentase dari pengujian grafis $80 \%$ baik, pengujian gameplay $70 \%$ baik, kenyaman pengguna $80 \%$ nyaman.

\section{Daftar Pustaka}

Adam G. Yowanda, Dwi Sunaryono, Ridho R. Hariadi, 2014, Rancang Bangun Aplikasi Papan Tulis Virtual dengan menggunakan 
Leap Motion, Institut Teknologi Sepuluh Nopember.

Ayung Candra Padmasari, 2014, 3- Dimensional Virtualclassroom for Journey Based on Hand Gesture Understanding using Leap Motion Controller. Universitas Negeri Malang Indonesia.

Michal Nowicki, Olgierd Pilarczyk, Jakub Wasikowski, 2014, Katarzyna Zjawin, Gesture Recognition Library for Leap Motion Controller. Bachelor's thesis. Poznan University of Tecnology.

Afdhol Dzikri, Rumen Filkov, 2014, Pelacakan Jari Tangan Menggunakan Data Kedalaman Berbasis Tracking. Universitas Gadjah Mada. 